\title{
Incision and flap design during total auricular reconstruction using a 2-stage strategy
}

\author{
Yangxue Ou\#, Tongyu Cao", Qingguo Zhang, Tun Liu \\ Department of Ear Reconstruction, Plastic Surgery Hospital, Chinese Academy of Medical Sciences, Peking Union Medical College, Beijing, China \\ Contributions: (I) Conception and design: Y Ou; (II) Administrative support: T Liu; (III) Provision of study materials or patients: T Liu, Q Zhang; (IV) \\ Collection and assembly of data: T Cao; (V) Data analysis and interpretation: T Cao; (VI) Manuscript writing: All authors; (VII) Final approval of \\ manuscript: All authors. \\ "These authors contributed equally to this work. \\ Correspondence to: Tun Liu. Department of Ear Reconstruction, Plastic Surgery Hospital, Chinese Academy of Medical Sciences, No. 33 Ba-Da-Chu \\ Road, Shi Jing Shan District, Beijing 100144, China. Email: liutun0224@163.com.
}

Background: Total auricular reconstruction is a challenge for plastic surgeons. Expanded flap method and Nagata's method with autologous costal cartilage are two leading techniques for ear reconstruction. And a two-stage strategy of expanded flap method received attention. In the present study, we report the incision and flap design of this strategy.

Methods: In the first stage, an $80 \mathrm{~mL}$ kidney-shaped expander was inserted in the mastoid region with the larger pole superiorly. The expander pocket was dissected subcutaneously in the scalp area and subfascially in the lower third region. In the second stage, the expander was removed from a Y-shaped lobule incision on the remanent ear. Then the remnant ear was separated into three flaps: the posterior skin flap, anterior skin flap, and lobule flap. When the framework was fabricated, the base frame and the underlying pad, which enhanced the projection, were fixed together as a whole to provide a more prominent appearance. The framework was totally wrapped into the expanded single flap without free skin grafting. Lobule transposition and tragus construction were performed simultaneously instead of a third-stage surgery. The recipient bed of rotated lobule was resected only to the epidermal layer and the subcutaneous layer was preserved to avoid central necrosis.

Results: A total of 21 patients received this strategy to reconstruct ear. With 3 months to 1.5 years of follow-up, 19 patients $(90.5 \%)$ were satisfied with the reconstructed ears. 3 patients $(14.3 \%)$ required further modification of reconstructed ear. No serious complications occurred during the procedures.

Conclusions: With a Y-shaped incision, three-flap design of remanent ear and lobule rotation to an epidermal-removal area, tissue expander removal and modification of remanent ear can be performed effectively to avoid necrosis and an extra operation.

Keywords: Microtia; auricular reconstruction; expanded flap

Submitted Nov 04, 2020. Accepted for publication Jan 06, 2021.

doi: 10.21037/atm-20-8015

View this article at: http://dx.doi.org/10.21037/atm-20-8015

\section{Introduction}

Many surgeons have made progress in the field of ear reconstruction. Brent and Nagata. demonstrated excellent results and with numerous modifications of Tanzer's technique (1-8). Nagata's 2-stage reconstruction is widely applied to auricular reconstruction, and the principles described by Nagata are considered the baseline for new ideas (9).

Tissue expansion provides additional soft tissue to cover the cartilage framework (9). Numerous ear reconstruction 
surgeons reported cases of ear reconstruction with tissue expansion (10-17). Neumann was the first one who introduced tissue expander for ear reconstruction (10). Park (12) developed a two-flap method with tissue expander, and Pan, Jiang, Zhang et al. modified this method $(13,14,18)$. Xing et al. further put forward a single flap method to avoid free skin graft (19). Kludt et al. presented the use of tissue expansion technique and Medpor framework to reconstruct ear (17). Tissue expansion is currently one of the most popular techniques for ear reconstruction. In a previously published study, our center presented the process and performance of a novel 2-stage strategy, which combined tissue expansion and Nagata's technique, for total ear reconstruction (20). In the present study, we will discuss this strategy further, in particular, the incision and flap design. We present the following article in accordance with the STROBE reporting checklist (available at http://dx.doi. org/10.21037/atm-20-8015).

\section{Methods}

During 2018-2019, 21 microtia patients (15 males and 6 females) underwent ear reconstructions using this new strategy at our center. The patients were aged 7 to 48 years. No patient had undergone previous operations or had trauma related in periauricular region. All 21 patients were unilateral microtia; 13 cases were right-side microtia and 8 were left. According to Nagata's definition, 17 cases were lobule type and 4 were concha-type microtia (5-7).

This study's procedures were approved by the Institutional Ethics Committee of Clinical Research (Plastic Surgery Hospital of CAMS\&PUMC). The study was conducted in accordance with the Declaration of Helsinki (as revised in 2013). Because of the retrospective nature of the research, the requirement for informed consent was waived.

\section{Statistical analysis}

Version 26.0 of the SPSS statistical software package (IBM, New York) was used to perform all statistical analyses. $\mathrm{P}<0.05$ was considered statistically significant.

\section{Surgical procedure}

\section{Stage 1: tissue expander insertion}

During expander implantation, a 4-cm incision within the postauricular scalp was made parallel to the temporal hairline. A dual-plan dissection is usually performed with a bounder between the upper and middle third regions; the upper third plane was above the postauricular fascia and the lower third subfascially. An $80 \mathrm{~mL}$ kidney-shaped expander was inserted to the pocket with the larger pole superiorly. Inflation began in the 7 th day postoperatively lasted for about 1.5 to 2 months, and the total expansion volume was $110-140 \mathrm{~mL}$. Laser hair removal was used twice for unhairing (Figure 1).

\section{Stage 2: total auricular reconstruction Design of skin incision}

A Y-shaped lobule incision was made to separate the remnant ear into 3 skin flaps as follows: (I) the posterior skin flap, which would cover the inter-tragus and posterior side of the tragus; (II) the anterior skin flap, which would cover the anterior side of the tragus; and (III) the lobule flap, which forming lobule and covering the inferior part of the framework. The remnant ear cartilage was completely removed, and great care was taken to preserve the integrity of the subdermal vascular plexus (Figure 2).

\section{Framework fabrication}

Before reconstruction, an X-ray film template was fashioned using the contralateral ear as a model. To harvest costal cartilages, a $2-5 \mathrm{~cm}$ oblique incision was made just above the costal margin of the contralateral side. The auricular framework was fabricated according to and Zhang's method with certain improvement $(3,4,15,21)$. The seventh and part of sixth costal cartilages were harvested for the base Frame, and the eighth cartilage for the helix. The scapha and fossa triangularis were obtained by sculpting the base frame. The antihelix was constructed from the remnant cartilage piece during scapha sculpting. The tragus was constructed by residual pieces from the seventh cartilage. To deepen the conchal cavity and ear's projection, a stable crescentshaped pad, which usually constitutes $\geq 2$ layers of cartilage pieces, was added beneath the base frame. For conchal-type microtia, there was no need to fabricate the tragus, intertragus, and antitragus (Figure 3).

\section{Expanded flap dissection}

Through the Y-shaped lobule incision, we inserted the capsule and removed the expander. The expander capsule and thickened skin flap along the edge of the expander were carefully removed. An expanded skin flap with a posterior pedicle was developed. The central zone of the flap enlarged from mastoid skin was considerably thin, and the total area was large enough to drape the cartilage framework and form a postauricular sulcus. After through hemostasis, the framework was inserted into the pocket of the expanded flap 

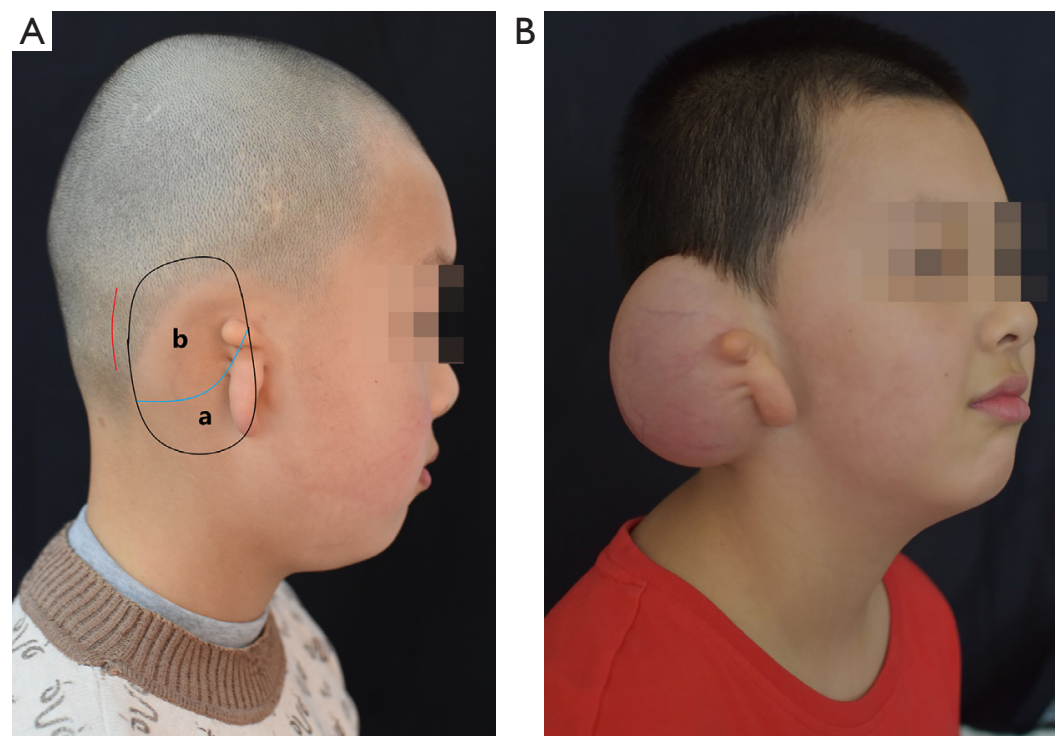

Figure 1 Tissue expansion. (A) Dual-plan dissection for tissue expander insertion. Red line indicates incision, and blue line indicates separating area. (a) Dissected subfascially; (b) dissected subcutaneously. (B) Complete inflation of the expander. Expander with greater upper poles helps to achieve exceeding expansion of the scalp. Hair removal using laser technique is effective to avoid a hair-bearing expanded scalp.

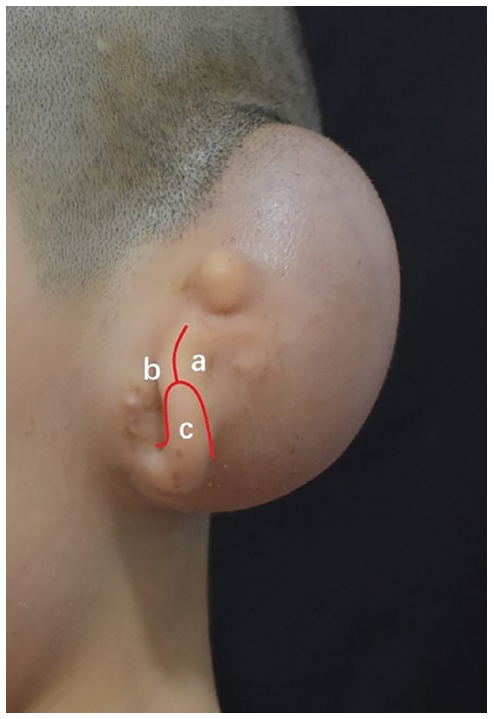

Figure 2 Remnant ear incision. Y-shaped lobule incision was made to separate the remnant ear into 3 skin flaps: (a) posterior flap; (b) anterior flap; (c) lobule flap. Red line indicates the incision.

and place in an appropriate position (Figure 4A,B,C).

\section{Lobule transposition and tragus formation}

To reconstruct the infrastructure of the ear, the lobule flap should rotate posteriorly and inferiorly. According to the position of the contralateral earlobe, the location of the lobule was predicted and marked. To avoid the slender contour at the joint of the reconstructed ear and the lobule, the distal extremity of the lobule should cover the tail of the helix for at least $2 \mathrm{~mm}$. Notably, for lobule transposition, we did not perform a full-thickness cut on the flap. We only resected the epidermal layer to preserve a subcutaneous pedicle. The blood supply of the conchae and antihelix skin was augmented by this pedicle. Finally, the tragus was covered by the posterior skin flap and the anterior skin flap of the remnant ear. After skin closure, the anatomical details of the framework were immediately evident with suction (Figure 4D,E).

\section{Results}

Follow-up was conducted from 3 months to 1.5 years after reconstruction. The reconstructed ears were evaluated by the patients (or the parents) and the surgeon.

Nineteen patients were satisfied with the reconstructed ears, which had good shape, as well as appropriate color, texture, size, and location (Figure 5). The cranio-auricular sulcus was also similar to the opposite ears. Four patients requested further modification (Table 1).

Few complications occurred during our procedure, 

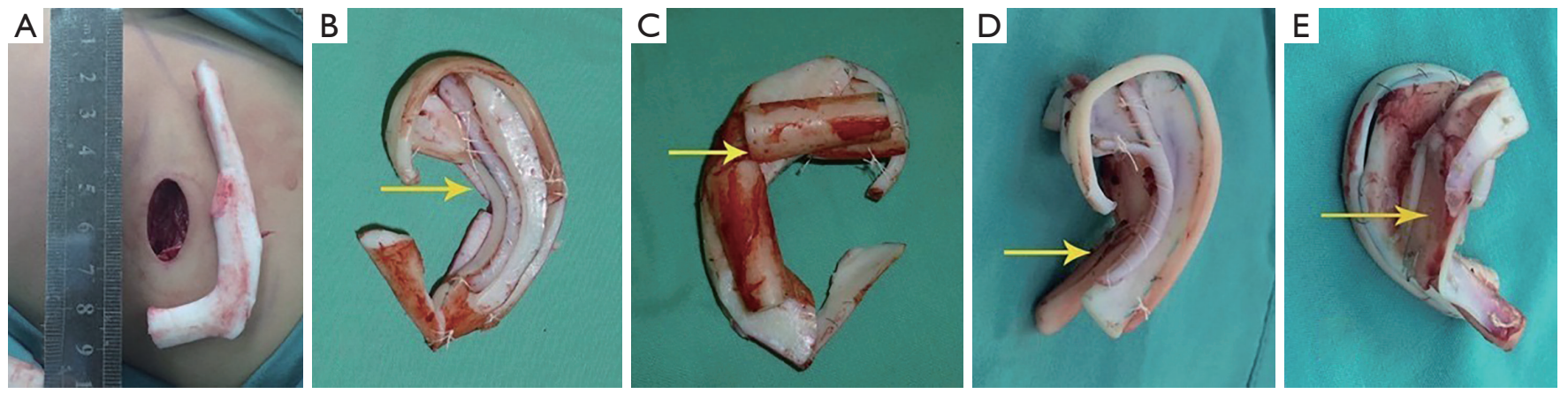

Framework fabrication. (A) Incision is about $2-5 \mathrm{~cm}$ in length to harvest costal cartilages. (B) Cartilage components to model the framework. Crura of antihelix and triangular fossa carved from the sixth cartilages; base frame carved from the seventh cartilages; antihelix made out of cartilage piece obtained during scapha sculpting; helix carved from the eighth cartilage. (C) Framework for lobule-type microtia. (D) Framework for concha-type microtia. (E) Dorsal view of the framework. Arrow indicates crescent-shaped pad beneath the base frame.
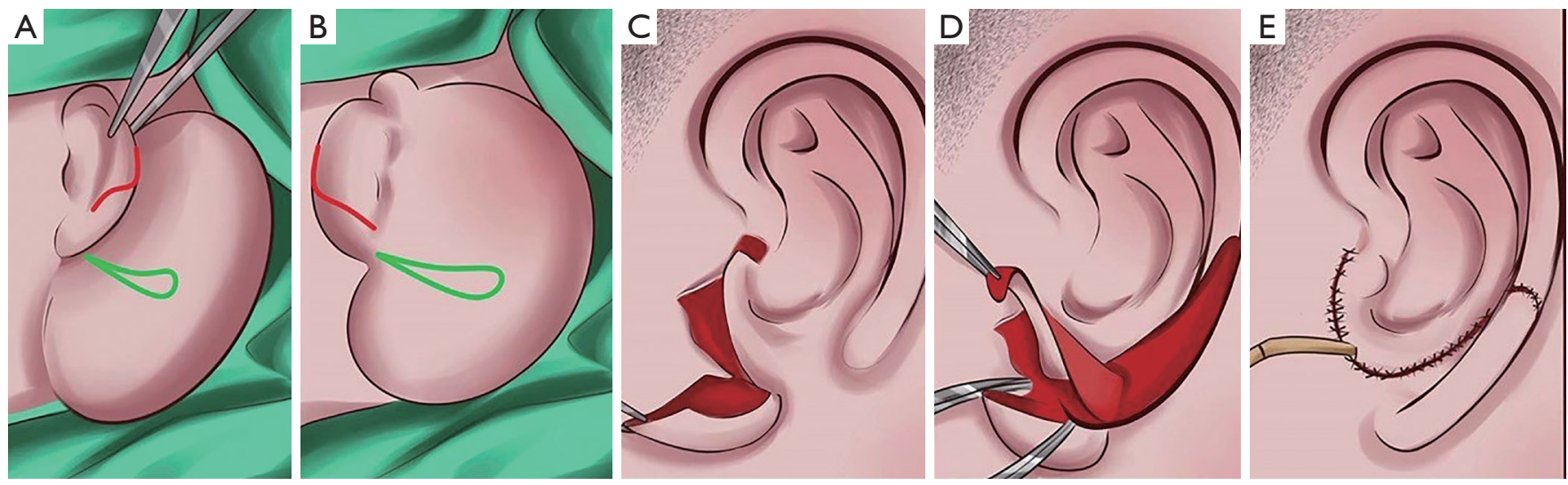

Figure 4 Lobule transposition. Lobule location was predicted and marked. Only the epidermal layer was resected to preserved a subcutaneous pedicle. Blood supply of the central area of posterior flap is augmented by this pedicle. Red line indicates incision; green line indicates subcutaneous pedicle.
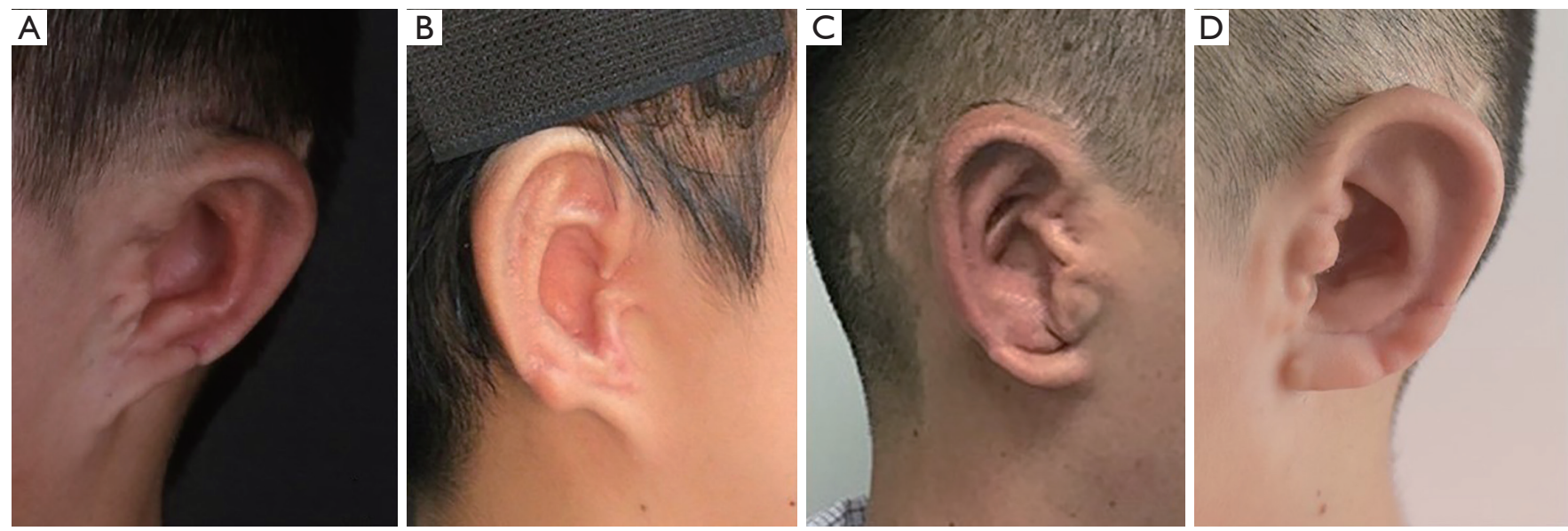

Figure 5 Reconstructed ears. 
Table 1 Reconstructed ear complaints

\begin{tabular}{lll}
\hline Complaint & Reason & $\begin{array}{l}\text { No. patients } \\
(\%)\end{array}$ \\
\hline Blunted convolution & Failure of negative suction & $1(4.8)$ \\
Unapparent projection & Excess contraction of flap & $1(4.8)$ \\
Helix incisura & Contraction of lobule flap & $1(4.8)$ \\
\hline
\end{tabular}

including 1 case of lobule blood crisis and 1 case of conchae skin blood crisis; the flaps survived after release tension and hydropathic compress. No other complications, such as exposure of the tissue expander, hematoma, skin necrosis, cartilage exposure, and infection, occurred.

\section{Discussion}

A sufficient skin envelope is the most important factor for a successful auricular reconstruction $(10,12,13)$. In most cases, a $\mathrm{W}$ - or $\mathrm{V}$-shaped posterior lobule incision on the remnant ear is an effective way to increase the skin surface area for framework coverage (5-7). However, in cases of tiny remnant ear or anotia, skin that was damaged by previous operation or trauma, poor skin mobility, low position of the hairline, or severe hemifacial microsomia, a tissue expansion procedure was necessary to provide additional hair-free skin to cover the framework (20-22).

Tissue expansion was first applied in auricular reconstruction by Neumann in 1957 (10). Although controversy around tissue expansion exists, a number of surgeons have successfully employed tissue expansion in the reconstruction of congenital microtia and traumatic auricular defects. In China, ear reconstruction surgeons reported thousands of microtia patients were reconstructed by skin expansion techniques (13,14,19-21,23-26). Usually, the expanded flap is not large enough to drape the entire framework, so skin grafts and postauricular facial flap elevation are consequently inevitable. Xing et al. and $\mathrm{Li}$ et al. described their novel strategies to avoid skin grafts; however, a surgical procedure with $\geq 3$ stages was still required $(19,26)$.

In previous study, a novel 2-stage strategy was presented, which combined tissue expansion and Nagata's technique. First, we inserted an $80 \mathrm{~mL}$ kidney-shaped expander into the mastoid region. In tissue expansion, the involvement of the surrounding scalp is usually difficult to avoid. As the scalp is thick and has hair, this can affect the final result. In our cases, we dissected subcutaneously in the scalp region and subfascially in the mastoid skin region. An expander with larger upper poles helps expand the scalp. As a result, the expanded scalp is equally thin as the mastoid skin.

We didn't select the initial incision of tissue expander implantation to remove the expander, which was described by a number of researchers who practice tissue expansion (25-28). During the second stage, a Y-shaped lobule incision on remanent ear was made to reach the expander and remove the capsule beside it. Through this incision, we also separated the lobule into 3 skin flaps: the posterior skin flap, the anterior skin flap, and the lobule flap.

In reconstructing the auricular framework, we added a crescent-shaped pad beneath the base frame to enhance projection and form a favorable cranio-auricular sulcus based on other researchers' experiences. A stable pad was essential to resist retraction of the flap and form a deep cavum concha. After we inserted the framework into the pocket of the expanded flap, a deep cranio-auricular sulcus was immediately evident.

During skin pocket preparation, Nagata emphasized that the subcutaneous pedicle effectively augments the flap's blood supply to avoid central necrosis (5). One of the advantages of tissue expansion is that the pocket prepared already in last stage and tissue expander can effectively improve the blood supply of expanded flap during a 1.5-2-month long expansion. In addition, in our strategy, the flap pocket was large enough to drape the entire frame, and lobule transposition was performed simultaneously. As the core concept of our strategy, a full-thickness incision on the expanded flap for lobule transposition was not made. We resected the epidermal layer, so that a subcutaneous pedicle was preserved to ensure the blood supply of the concha and antihelix skin.

In the present study, we developed a novel 2-stage strategy, which combined tissue expansion with Nagata' technique, on total ear reconstruction. The key points of our technique are as follows:

(I) We inserted an $80 \mathrm{ml}$ kidney-shaped expander, with a larger upper pole in the scalp region. We dissected subcutaneously in the scalp area and subfascially in the lower third region. Laser hair removal was also applied to avoid hairy skin at the superior helix.

(II) A Y-shaped lobule incision was made to remove the expander and the capsule beside it. Through this incision, we also removed the remnant cartilage and separated the remnant ear into the posterior skin flap, anterior skin flap, and the lobule flap.

(III) A full-thickness incision on the flap for lobule transposition was not made. We only resected the 
epidermal layer; therefore, a subcutaneous pedicle was preserved to avoid central necrosis.

(IV) We made a 2-5 cm incision to harvest the cartilages. We added a crescent-shaped pad beneath the base frame to enhance projection and form a cranioauricular sulcus.

(V) The flap was large enough to drape the whole frame; skin grafts and facial flap elevation were completely avoided. This reduces the need for 3 -stage surgery for lobule transposition and tragus fabrication.

\section{Acknowledgments}

Funding: None.

\section{Footnote}

Reporting Checklist: The authors have completed the STROBE reporting checklist. Available at http://dx.doi. org/10.21037/atm-20-8015

Data Sharing Statement: Available at http://dx.doi. org/10.21037/atm-20-8015

Conflicts of Interest: All authors have completed the ICMJE uniform disclosure form (available at http://dx.doi. org/10.21037/atm-20-8015). The authors have no conflicts of interest to declare.

Ethical Statement: The authors are accountable for all aspects of the work in ensuring that questions related to the accuracy or integrity of any part of the work are appropriately investigated and resolved. This study's procedures were approved by the Institutional Ethics Committee of Clinical Research (Plastic Surgery Hospital of CAMS\&PUMC). The study was conducted in accordance with the Declaration of Helsinki (as revised in 2013). Because of the retrospective nature of the research, the requirement for informed consent was waived.

Open Access Statement: This is an Open Access article distributed in accordance with the Creative Commons Attribution-NonCommercial-NoDerivs 4.0 International License (CC BY-NC-ND 4.0), which permits the noncommercial replication and distribution of the article with the strict proviso that no changes or edits are made and the original work is properly cited (including links to both the formal publication through the relevant DOI and the license). See: https://creativecommons.org/licenses/by-nc-nd/4.0/.

\section{References}

1. Tanzer RC. Total reconstruction of the external ear. Plast Reconstr Surg Transplant Bull 1959;23:1-15.

2. Brent B. The correction of microtia with autogenous cartilage grafts: I. The classic deformity? Plast Reconstr Surg 1980;66:1-12.

3. Brent B. The correction of microtia with autogenous cartilage grafts: II. Atypical and complex deformities. Plast Reconstr Surg 1980;66:13-21.

4. Nagata S. A new method of total reconstruction of the auricle for microtia. Plast Reconstr Surg 1993;92:187-201.

5. Nagata S. Modification of the stages in total reconstruction of the auricle: Part I. Grafting the three-dimensional costal cartilage framework for lobule-type microtia. Plast Reconstr Surg 1994;93:221-30; discussion 267-8.

6. Nagata S. Modification of the stages in total reconstruction of the auricle: Part II. Grafting the three-dimensional costal cartilage framework for concha-type microtia. Plast Reconstr Surg 1994;93:231-42; discussion 267-8.

7. Nagata S. Modification of the stages in total reconstruction of the auricle: Part III. Grafting the three-dimensional costal cartilage framework for small concha-type microtia. Plast Reconstr Surg 1994;93:243-53; discussion 267-8.

8. Nagata S. Modification of the stages in total reconstruction of the auricle: Part IV. Ear elevation for the constructed auricle. Plast Reconstr Surg 1994;93:254-66; discussion 267-8.

9. Firmin F. Ear reconstruction in cases of typical microtia. Personal experience based on 352 microtic ear corrections. Scand J Plast Reconstr Surg Hand Surg 1998;32:35-47.

10. Neumann CG. The expansion of an area of skin by progressive distention of a subcutaneous balloon; use of the method for securing skin for subtotal reconstruction of the ear. Plast Reconstr Surg (1946) 1957;19:124-30.

11. Hata Y, Hosokawa K, Yano K, et al. Correction of congenital microtia using the tissue expander. Plast Reconstr Surg 1989;84:741-51; discussion 752-3.

12. Park C. Subfascial expansion and expanded two-flap method for microtia reconstruction. Plast Reconstr Surg 2000;106:1473-87.

13. Pan B, Jiang H, Guo D, et al. Microtia: ear reconstruction using tissue expander and autogenous costal cartilage. J Plast Reconstr Aesthet Surg 2008;61 Suppl 1:S98-103.

14. Zhang Q, Quan Y, Su Y, et al. Expanded retroauricular 
skin and fascial flap in congenital microtia reconstruction. Ann Plast Surg 2010;64:428-34.

15. Tanino R, Miyasaka M. Reconstruction of microtia using tissue expander. Clin Plast Surg 1990;17:339-53.

16. Dashan Y, Haiyue J, Qinghua Y, et al. Technical innovations in ear reconstruction using a skin expander with autogenous cartilage grafts. J Plast Reconstr Aesthet Surg 2008;61 Suppl 1:S59-69.

17. Kludt NA, Vu H. Auricular reconstruction with prolonged tissue expansion and porous polyethylene implants. Ann Plast Surg 2014;72 Suppl 1:S14-7.

18. Jiang H, Pan B, Lin L, et al. Ten-year experience in microtia reconstruction using tissue expander and autogenous cartilage. Int J Pediatr Otorhinolaryngol 2008;72:1251-9.

19. Xing W, Kang C, Wang Y, et al. Reconstruction of Microtia Using a Single Expanded Postauricular Flap without Skin Grafting: Experience of 683 Cases. Plast Reconstr Surg 2018;142:170-9.

20. Chen Q, Zhang J, Wang B, et al. Total Auricular Reconstruction Using a Single Extended Postauricular Flap Without Skin Grafting in Two Stages: Experiences of 106 Cases. Aesthetic Plast Surg 2020;44:365-72.

21. Qian J, Li Z, Liu T, et al. Auricular Reconstruction in Hemifacial Microsomia with an Expanded Two-Flap Method. Plast Reconstr Surg 2017;139:1200-9.

22. Guo P, Pan B, Jiang H, et al. Burned Ear Reconstruction

Cite this article as: Ou Y, Cao T, Zhang Q, Liu T. Incision and flap design during total auricular reconstruction using a 2-stage strategy. Ann Transl Med 2021;9(1):61. doi: 10.21037/ atm-20-8015
Using the Combination of an Expanded Postauricular Scar Skin Flap and a Postauricular Fascial Flap. Facial Plast Surg 2020. [Epub ahead of print].

23. Jiang H, Pan B, Lin L, et al. Fabrication of threedimensional cartilaginous framework in auricular reconstruction. J Plast Reconstr Aesthet Surg 2008;61 Suppl 1:S77-85.

24. Wang $\mathrm{Y}$, Zhuang $\mathrm{X}$, Jiang $\mathrm{H}$, et al. The anatomy and application of the postauricular fascia flap in auricular reconstruction for congenital microtia. J Plast Reconstr Aesthet Surg 2008;61 Suppl 1:S70-6.

25. Chen Z, Zhang W, Huang J, et al. Exceedingly expanded retroauricular flaps for microtia reconstruction. J Plast Reconstr Aesthet Surg 2011;64:1448-53.

26. Li C, Jiang H, Huang C, et al. A new strategy for total auricular reconstruction using prelamination of an extended retroauricular flap with tissue expansion. J Plast Reconstr Aesthet Surg 2016;69:819-26.

27. Zhang GL, Zhang JM, Liang WQ, et al. Implant double tissue expanders superposingly in mastoid region for total ear reconstruction without skin grafts. Int J Pediatr Otorhinolaryngol 2012;76:1515-9.

28. Park BY, Im JT, Lim SY, et al. Microtia reconstruction using tissue expanders without skin grafts from groin region. J Plast Reconstr Aesthet Surg 2014;67:1481-7.

(English Language Editor: C. Betlazar-Maseh) 